\title{
Study of the Computational Domain Effect on the Aerodynamic Structure Around a Savonius Wind Rotor
}

\author{
Sobhi Frikha, Zied Driss, Hedi Kchaou, Mohamed Salah Abid \\ Laboratory of Electro-Mechanic Systems (LASEM), National School of Engineers of Sfax (ENIS), University of Sfax (US), Sfax, TUNISIA
}

Email address:

Frikha_sobhi@yahoo.fr(S. Frikha), zied.driss@enis.rnu.tn (Z. Driss), hedi.kchaou@ipeis.rnu.tn (H. Kchaou),

MohamedSalah.Abid@enis.rnu.tn (M. S. Abid)

\section{To cite this article:}

Sobhi Frikha, Zied Driss, Hedi Kchaou, Mohamed Salah Abid. Study of the Computational Domain Effect on the Aerodynamic Structure Around a Savonius Wind Rotor. International Journal of Fluid Mechanics \& Thermal Sciences. Vol. 1, No. 2, 2015, pp. 20-24.

doi: $10.11648 /$ j.ijfmts.20150102.11

\begin{abstract}
This study aims to investigate the effect of the computational domain on aerodynamic characteristics of the flow around a Savonius wind rotor. For thus, we have developed a numerical simulation using CFD code. The considered numerical model is based on the resolution of the Navier-Stokes equations in conjunction with the standard k- $\varepsilon$ turbulence model. These equations were solved by a finite volume discretization method. Particularly, we are interested to visualize the velocity field, the mean velocity and the static pressure. The good comparison of our numerical results with anterior results confirms the validity of the numerical method.
\end{abstract}

Keywords: Turbulent Flow, Savonius Wind Rotor, CFD

\section{Introduction}

Renewable energies are clean and inexhaustible energy that preserve the environment. They are provided by the sun, the wind, the waves or the heat of the earth's core. In recent years, an interest in wind energy has been growing and wind turbines are developed to generate electricity from the kinetic power of the wind. Wind turbines can rotate about either a horizontal or a vertical axis. One advantage of the vertical-axis wind turbines is that the turbine does not need to be pointed into the wind to be effective. Savonius wind rotors are a type of vertical-axis wind turbine. It is a drag-type device. Although with less efficiency compared with three-bucket wind turbines, the Savonius wind rotor has the advantage of being compact, economical and aesthetic. This allows it to be easily integrated into buildings. Savonius wind rotors have good starting characteristics, operate at relatively low operating speeds and have ability to accept wind from any direction. For several years, many studies have significantly improved the performance of Savonius rotors. For example Kamoji et al. [1] investigated the performance of modified forms of conventional rotors with and without central shaft between the end plates. Menet and Bourabaa [2] tested different configuration of the savonius rotor and found that the best value of the static torque coefficient is obtained for an incidence angle equal to $\theta=45^{\circ}$ and a relative overlap equal to $\mathrm{e} / \mathrm{d}=0.24$. They compared their numerical results with those obtained by Blachwell et al. [3] and a good agreement was obtained. Ushiyama and Nagai [4] tested several parameters of the Savonius rotor including gap ratio, aspect ratio, number of cylindrical buckets, number of stages, endplate effects, overlap ratio, and bucket design. The highest efficiency of all configurations tested was $24 \%$ for a two-stage, two-bucket rotor. Driss et al. [5] conducted a computational fluid dynamic study to present the local characteristics of the turbulent flow around Savonius wind rotor. They compared their numerical results to experimental results and a good agreement was obtained. Grinspan et al. [6] developed a new blade shape with a twist for the Savonius rotor. They obtained a maximum power coefficient of 0.5 with this model. Saha and Rajkumar [7] compared the performance of a bladed metallic Savonius rotor to a conventional semi-circular blade having no twist. The twist produced good starting torque and larger rotational speeds and gives an efficiency of 0.14 . The best torque was obtained with blades twisted by an angle $\alpha=12.5^{\circ}$. Akwa et al. [8] studied the influence of the buckets overlap ratio of a Savonius wind rotor on the averaged torque and power coefficients by changing the geometry of the rotor. They notice that the maximum device performance occurs for buckets overlap ratios with values close to 0.15 . Khan et al. [9] tested different blade profiles of a Savonius rotor both in tunnel and natural wind conditions and they varied the overlap. 
The highest $\mathrm{Cp}$ of 0.375 was obtained for blade profile of S-section Savonius rotor at an optimum overlap ratio of $30 \%$.

In this context, we are interested in studying the flow around a Savonius wind rotor. We develop numerical simulations of the turbulent flow using a CFD code and we investigate the effect of the computational domain on the aerodynamic characteristics of the flow.

\section{Geometric Parameters}

The examined Savonius wind rotor consists of two half-cylinder buckets of diameter $\mathrm{d}=0.3 \mathrm{~m}$. The overlap is equal to $\mathrm{e}=72 \mathrm{~mm}$ (Figure 1 ).

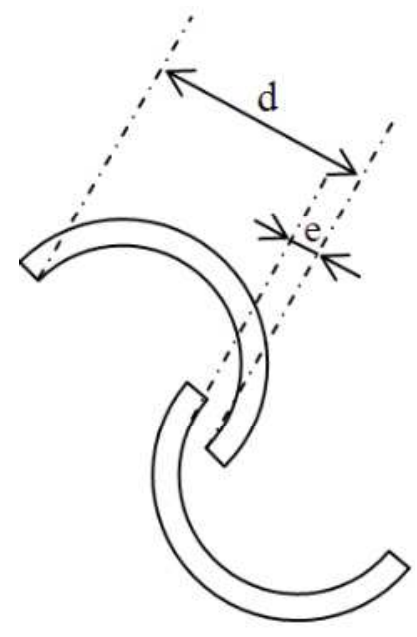

Fig. 1. Savonius wind rotor.

\section{Numerical Model}

Computational fluid dynamic (CFD) simulations were conducted using "Fluent 6.3". The boundary conditions are defined by a velocity inlet equal to $\mathrm{V}=5 \mathrm{~m} . \mathrm{s}^{-1}$ and a pressure outlet equal to $\mathrm{P}=1 \mathrm{~atm}$. For the choice of the numerical model, we are interested on the study the effect of the computational domain. Four different dimensions are considered characterized by $2 \mathrm{~m} \times 1 \mathrm{~m}$ (Figure 2.a), $3 \mathrm{~m} \times 2 \mathrm{~m}$ (Figure 2.b), $4.5 \mathrm{~m} \times 3.5 \mathrm{~m}$ (Figure 2.c) and $6 \mathrm{~m} \mathrm{x} 4 \mathrm{~m}$ (Figure 2.d). In these different cases, the number of cells is equal to 5000, 15000, 40000 and 60000 respectively.

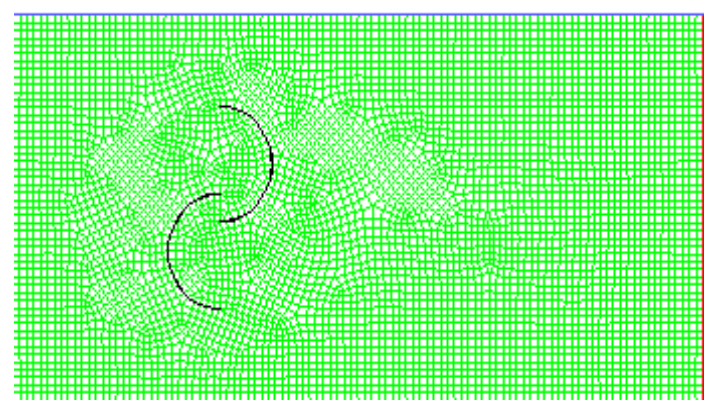

(a) 5000 cells

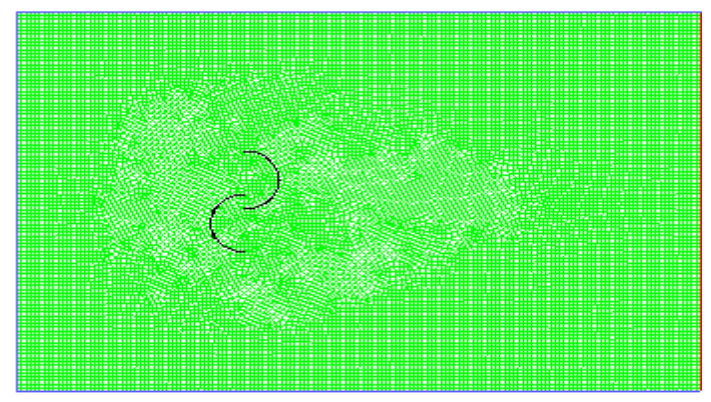

(b) 15000 cells

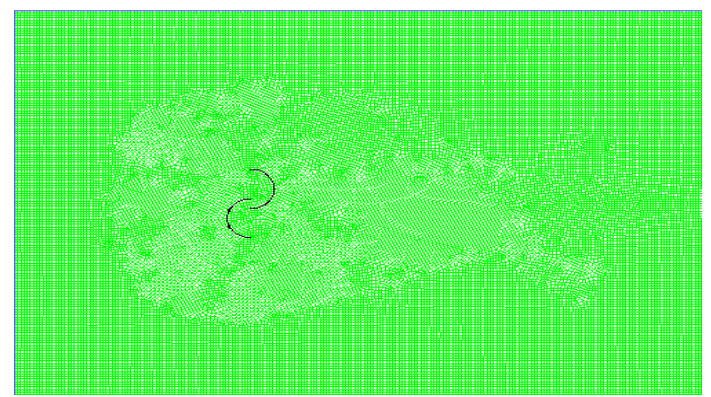

(c) 40000 cells

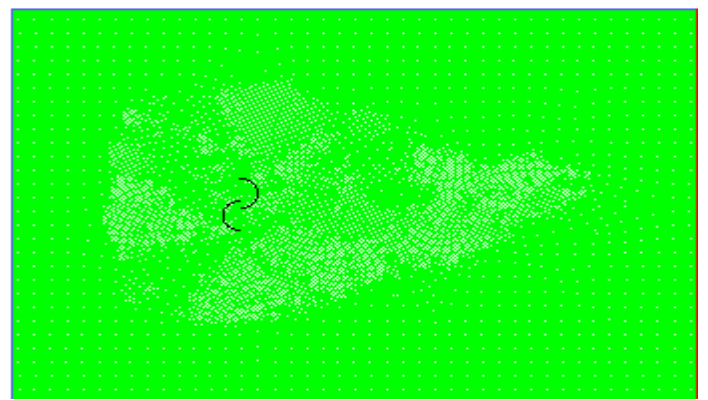

(d) 60000 cells

Fig. 2. Different computational domains.

\section{Numerical Results}

\subsection{Velocity Field}

Figure 3 presents the distribution of the velocity fields for different control domains. According to these results, it has been noted a similarity in the distribution of the velocity fields. In the inlet, the flow appears uniform and has a value of $\mathrm{V}=5$ $\mathrm{m} . \mathrm{s}^{-1}$ which is imposed by the boundary conditions. On the meeting of the buckets, a flow deceleration appears at both concave and convex surfaces of the rotor. However, at the attack side, an acceleration of the flow has been observed. In the external attack side of the buckets, the velocity increases. Behind the rotor, there is a rapid deceleration of the velocity and the formation of two recirculation zones downstream of the two buckets. By increasing the computational domain, it has been noted that the maximum values of the velocity decrease. In these conditions, they are equal to $\mathrm{V}=11.7 \mathrm{~m} . \mathrm{s}^{-1}$ (Figure 3. a), $\mathrm{V}=8.14 \mathrm{~ms}^{-1}$ (Figure 3.b), $\mathrm{V}=7.35 \mathrm{~ms}^{-1}$ (Figure 3.c) and $\mathrm{V}=7.03 \mathrm{~ms}^{-1}$ (Figure 3.d). In the internal attack side of the buckets, some asymmetry has been observed. Indeed, the velocity reaches a large value in the lower attack side 
compared to the upper attack side.

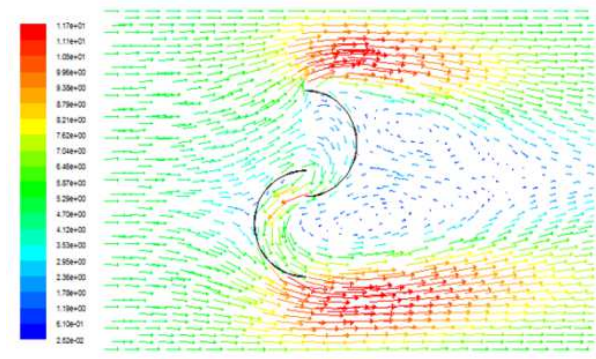

(a) 5000 cells

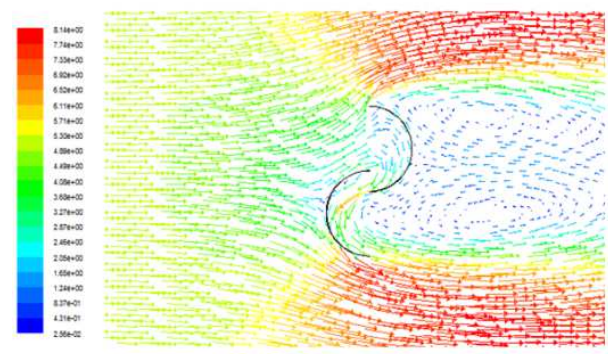

(b) 15000 cells

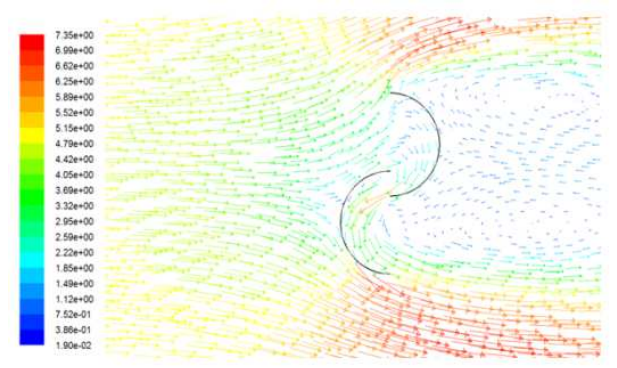

(c) 40000 cells

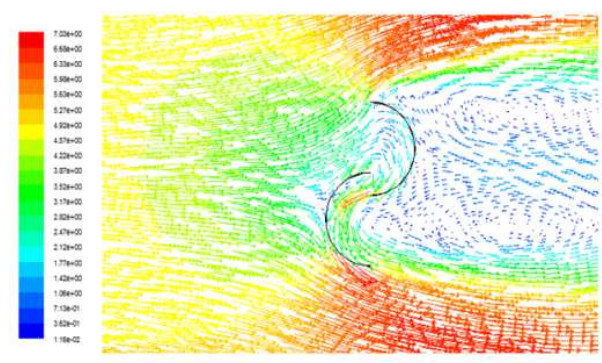

(d) 60000 cells

Fig. 3. Distribution of the velocity fields.

\subsection{Mean Velocity}

Figure 4 presents the distribution of the mean velocity for different control domains. In the inlet, the mean velocity is equal to the value imposed by the boundary conditions which is $5 \mathrm{~ms}^{-1}$. This value decreases and achieved zero at the meeting of the two buckets. In the internal attack side of the upper bucket, an increase of the mean velocity is followed by a decrease. This fact is due to the infiltration of air between the two buckets. An increase of the mean velocity is also observed at the external attack side of the buckets. From these two attack side, two wakes characteristics of the maximum values of the mean velocity are developed. These two wakes extend downstream of the attack zones. Behind the rotor, it has been observed that the value of the mean velocity decreases rapidly. This decrease begins just downstream of the rotor and extends to the limits of the control volume. By comparing these results, it appears that the means velocity decreases while increasing the computational domain. Indeed, for the four areas studied, the maximum values of the mean velocity are equal to 11.7 $\mathrm{ms}^{-1}$ (Figure 4.a), $7.91 \mathrm{~ms}^{-1}$ (Figure 4.b), $6.92 \mathrm{~ms}^{-1}$ (Figure 4.c) and $6.62 \mathrm{~ms}^{-1}$ (Figure 4.d).

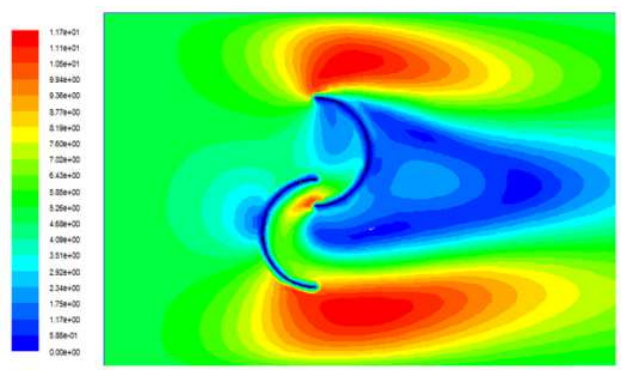

(a) 5000 cells

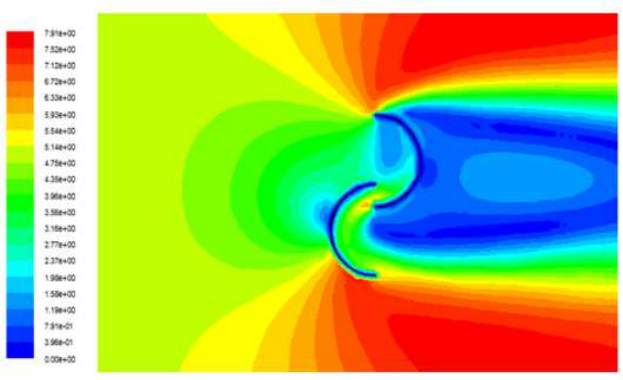

(b) 15000 cells

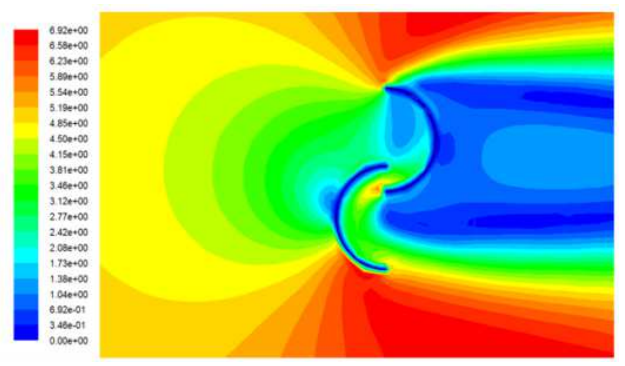

(c) 40000 cells

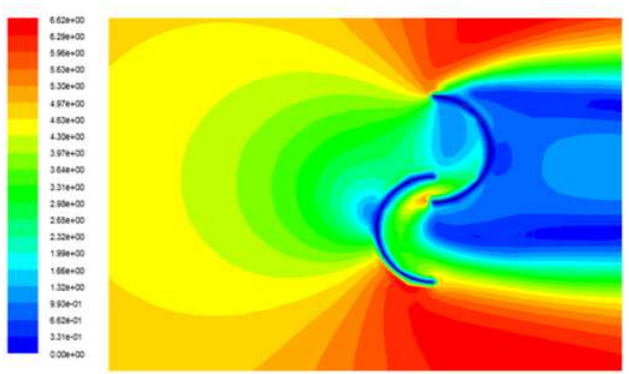

(d) 60000 cells

Fig. 4. Distribution of the mean velocity. 


\subsection{Static Pressure}

Figure 5 presents the distribution of the static pressure for different control domains. According to these results, a high pressure appears upstream of the Savonius rotor which is accentuated at the concave surface of the buckets and on the upper convex portion of the lower bucket of the Savonius rotor. In the concave surface of the lower bucket, it has been observed a rapid decrease in values of the static pressure. However, a depression appears significantly at the convex surface of the upper bucket. The most important areas of depression appear in the two attack zones of the upper bucket of the Savonius rotor. The depression zone extends downstream of the rotor to the output of the control volume. Indeed, it has been noted that the values the static pressure decreases with the increase of the computational domain. Infact, for the four studied domains, the pressure values are equal to $103 \mathrm{~Pa}$ (Figure 5.a), 40.2 $\mathrm{Pa}$ (Figure 5.b) $32.2 \mathrm{~Pa}$ (Figure 5.c) and 26.6 Pa (Figure 5.d).

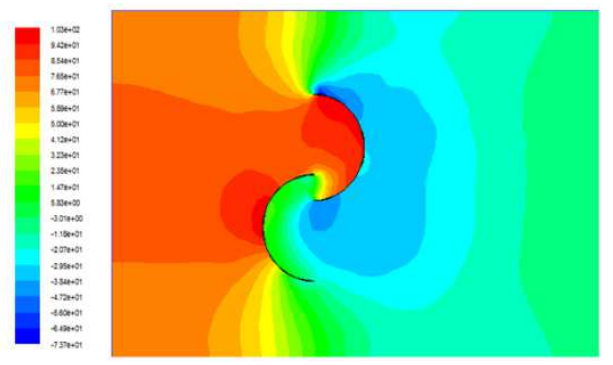

(a) 5000 cells

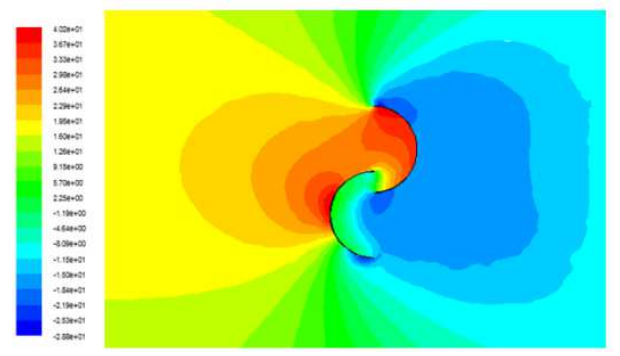

(b) 15000 cells

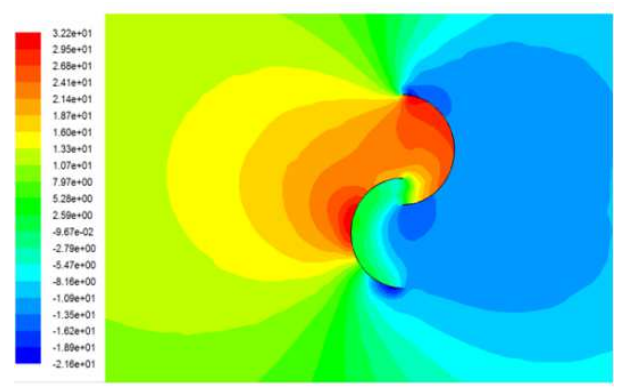

(c) 40000 cells

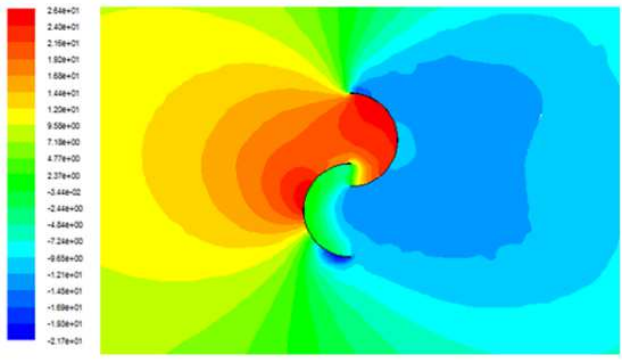

(d) 60000 cells

Fig. 5. Distribution of the static pressure.

\section{Comparison with Anterior Results}

In this section, we are interested in comparing our numerical results with previous work [10]. The values of the static torque coefficients found for different control domains are presented in table 1 and compared with those found by Menet and Cottier [10]. According to those results, it has been observed that the third domain gives the best results. Indeed, in these conditions, the calculated value is very close to that found by Menet and Cottier [10].

Table 1. Static moment coefficients for different domains.

\begin{tabular}{llllll}
\hline & \multicolumn{2}{l}{ Cells numbers } & & $\begin{array}{l}\text { Menet and } \\
\text { Cottier [10] }\end{array}$ \\
\cline { 2 - 5 } & $\mathbf{5 0 0 0}$ & $\mathbf{1 5 0 0 0}$ & $\mathbf{4 0 0 0 0}$ & $\mathbf{6 0 0 0 0}$ & 0.33 \\
\hline $\mathrm{C}_{\mathrm{Ms}}$ & 0.98 & 0.45 & 0.34 & 0.31 & 0.33 \\
\hline
\end{tabular}

\section{Conclusions}

In this work, numerical simulations have been developed to study the effect of the computational domain on the aerodynamic characteristics of the flow around the Savonius wind rotor. We present the velocity, the mean velocity and the static pressure. According to the numerical results, it has been observed that the computational domain has a direct effect on the aerodynamic characteristics. The comparison of the static torque coefficients with those given by Menet and Cottier [5] is performed. A good agreement was obtained and confirmed the numerical method. In the future, we propose to study the effect of the incidence angle and the overlap of the buckets.

\section{References}

[1] M.A. Kamoji, S.B. Kedare, S.V. Prabhu, Experimental investigations on single stage modified Savonius rotor, Applied Energy, Vol. 86, 1064-1073, 2009.

[2] Blackwell B.F., Sheldahl R.E., Feltz L.V., Wind Tunnel performance data for two and three-bucket Savonius rotor. Journal of Energy 2-3 160-164, 1978.

[3] Ushiyama, I., Nagai, H., Optimum design configurations and performances of Savonius rotors. Wind Eng. 12-1, 59-75, 1988.

[4] J.L. Menet, N. Bourabaa, Increase in the Savonius rotors efficiency via a parametric investigation. European Wind Energy Conference, London, 2004. 
[5] Z. Driss and M. S. Abid, Numerical Investigation of the Aerodynamic Structure Flow around Savonius Wind Rotor, Science Academy Transactions on Renewable Energy Systems Engineering and Technology, Vol. 2, No. 2, 196-204, 2012.

[6] A.S. Grinspan, P.S. Kumar, U.K. Saha, P. Mahanta, Ratnarao DV, Veda Bhanu G., Design, development \& testing of Savonius wind turbine rotor with twisted blades. Proceedings of international conference on fluid mechanics \& fluid power, India, 28, 28-31, 2001.

[7] U.K. Saha, M. Rajkumar, On the performance analysis of Savonius rotor with twisted blades, J. Renew. Energy, pp. 960-1481, 2005.
[8] J.V. Akwa, G.A. Júnior, A.P. Petry, Discussion on the verification of the overlap ratio influence on performance coefficients of a Savonius wind rotor using computational fluid dynamics. Renewable Energy, 38, 141-149, 2012.

[9] N. Khan, I. M. Tariq, M. Hinchey, V. Masek, Performance of Savonius Rotor as Water Current Turbine, Journal of Ocean Technology, 4, N. 2, pp. 27-29, 2009.

[10] J.L. Menet, F. Cottier, Étude paramétrique du comportement aérodynamique d'une éolienne lente à axe vertical de type Savonius. 16è Congrès Français de Mécanique, Nice, 2003. 